\title{
Alarm System Problem Identified
}

National Cancer Institute

\section{Source}

National Cancer Institute. Alarm System Problem Identified. NCI Thesaurus. Code

C139506.

A system intended to warn of a potentially unsafe condition did not operate correctly. 